\title{
UTILIZAÇÃO DA CATEGORIZAÇÃO DE LINDEN E DA ESTRATÉGIA INFERENCIAL DE LEITURA PARA O ESTUDO DAS RELAÇÕES TEXTO-IMAGEM EM LIVROS INFANTIS ILUSTRADOS SOB O OLHAR DO DESIGN DA INFORMAÇÃO
}

\author{
Guilherme Mendes Cahú Costa (discente)/UFPE \\ Solange Galvão Coutinho (orientadora)/UFPE
}

\section{RESUMO}

Este artigo apresenta a estratégia inferencial de leitura de Tavares (2019) e a categorização de Linden (2011) como ferramental analítico para estudo do livro ilustrado, objetivando introduzi-los ao campo do Design da Informação. A exposição destes métodos é seguida de dois exemplos de análise de relações-texto imagem do livro infantil A Menina do Picolé Azul (2016) da Companhia Editora de Pernambuco (Cepe), onde ressaltamos a dinâmica comunicacional entre texto e imagem.

Palavras-chave: Design da Informação; Literatura Infantil; Livro Ilustrado; Estratégia Inferencial de Leitura; Sophie Van der Linden.

\section{Introdução}

Amplamente realizado no campo da Literatura, o estudo do livro ilustrado ainda demanda mais adeptos no campo do Design da Informação (DI). Com a compreensão de que a área do Design da Informação se preocupa fortemente com a configuração da mensagem (JACOBSON, 1999; REDIG, 2004; SBDI, 2020), a mesma mostra-se propícia para um maior aprofundamento desse objeto de estudo. Neste artigo apresentamos a metodologia analítica, responsável pela interpretação do livro ilustrado e pela categorização de suas relações texto-imagem, utilizada na dissertação de Costa (2021, no prelo $)^{1}$. Com isso, desejamos proporcionar aos interessados no Design da Informação um ferramental analítico útil ao estudo do livro ilustrado, porém ainda incomum ao campo.

Neste sentido, o objetivo deste artigo é apresentar a estratégia inferencial de leitura de Tavares (2019) e a categorização de Linden (2011) como contribuição metodológica ao campo do Design da Informação para a análise de livros ilustrados.

\section{Métodos de análise}

Apresentaremos a categorização do livro ilustrado elaborada por Linden (2011) e abordaremos a estratégia inferencial de leitura proposta por Tavares (2019). Demonstraremos a relevância da utilização desses métodos em conjunto através de dois exemplos de análise. 


\section{Categorização de Linden}

Linden (2011) considera que não é possível julgar o livro como um todo, apresentando-lhe uma única acepção, porque nele pode existir mais de um tipo de relação texto-imagem. Não se pode, por exemplo, dizer que um livro seja redundante por completo, se o mesmo possuir outros tipos de relação. Desta forma, a autora propõe categorias para: (a) diagramação: dissociação, associação, compartimentação e conjunção; (b) funções do texto: limitação, ordenação, regência e ligação; (c) relações texto-imagem: redundância, colaboração e disjunção; e (d) para o modo como essas duas instâncias da comunicação interagem entre si nessas relações: repetição, seleção, revelação, completude, contraponto e amplificação (COSTA, 2021, no prelo).

A categorização de Linden (2011) mostra-se proveitosa por três razões: (1) maior especificidade quanto à interação entre texto e imagem; (2) boa clareza na explanação; e, (3) maior aprofundamento proporcionado à investigação. Apresentamos uma breve descrição das categorias a seguir, a partir de Costa (2021, no prelo).

\section{(a) Diagramação}

Articuladora entre texto e imagem na página, pode ocorrer de diversas maneiras no livro. Assim são classificadas:

Dissociação: texto se encontra numa página e imagem na outra.

Associação: texto e imagem se encontram na mesma página simples ou dupla, podendo o texto estar localizado acima, abaixo ou ao lado da imagem. Quando a imagem ocupa a página inteira, o texto pode acompanhá-la por uma caixa ou de um espaço específico com poucos detalhes.

Compartimentação: similar aos quadros de uma história em quadrinhos. No caso do livro ilustrado, não costumam ser pequenos e ocupam um espaço generoso na página.

Conjunção: o texto é parte integrante da imagem, compartilhando o espaço com elementos visuais e formando, com ela, uma composição visual única. Esta disposição sugere uma leitura intercalada entre as palavras e elementos da ilustração.

(b) Funções do texto

Indicam como o texto lida com a continuidade da narrativa ao promover conexão entre diferentes páginas, induzir a leitura de componentes pictóricos isoladamente ou em conjunto e demonstrar passagem de tempo. 
Limitação: onde cada trecho textual induz a leitura de componentes pictóricos isoladamente. Pode haver várias imagens na mesma página com um pequeno texto para cada. Alternativamente, uma única imagem pode ser acompanhada de textos separados, sugerindo leitura sequencial.

Ordenação: texto, normalmente em bloco único, que informa a ordem de acontecimentos simultâneos representados pictoricamente.

Regência: texto que indica a passagem de tempo fictício, comumente identificado pelo uso de advérbios de tempo.

Ligação: texto que ajuda a conectar acontecimentos entre a página anterior e a atual, ou entre a atual e a posterior. Ajuda a manter a coesão narrativa quando há ruptura temporal, espacial ou de estado das coisas entre diferentes páginas ou imagens.

(c) Relações entre texto e imagem

Redundância: segundo Linden (2011), "a redundância se refere à congruência do discurso, o que não impede, por exemplo, que a imagem forneça detalhes sobre cenários ou desenvolva um discurso estético específico" (Ibid. p. 120). Nota-se redundância quando há a sensação de que texto e imagem dizem a mesma coisa.

Colaboração: quando o sentido é construído em conjunto do texto com a imagem. A eliminação de uma dessas instâncias prejudicaria seriamente a comunicação da história.

Disjunção: quando texto e imagem divergem entre si. Podem se contradizer diretamente ou seguir caminhos paralelos, em que se ignoram.

(d) Modos de interação entre texto e imagem nas relações

Estes modos lançam luz sobre como as relações entre texto e imagem são configuradas. Para identificar como isso ocorre, Linden (2011) trata texto e imagem como instâncias da comunicação e pondera sobre o conceito de primazia. Uma instância pode ser considerada como primária por ser lida primeiro, enquanto a outra seria, então, considerada secundária. É comum que a instância secundária interfira na compreensão da primária, como se atualizasse o sentido dela. Pode ser difícil identificar a primazia na página, provocando no leitor uma leitura cíclica entre texto e imagem. Também é possível que, em leituras subsequentes, a dinâmica de primazia mude aos olhos do leitor, podendo o mesmo acontecer com a interpretação das interações e relações entre texto e imagem. Nota-se que o conceito de primazia é influenciado tanto pela diagramação, quanto pela configuração visual do texto e da imagem, bem como pela condução da história. 
Para Linden (Ibid.), o modo como essas duas instâncias da comunicação interagem entre si dá-se por repetição, seleção, revelação, completude, contraponto e amplificação. Em nossa compreensão, as relações de redundância são provocadas por interações de repetição (Figura 1).

\title{
REDUNDÂNCIA
}

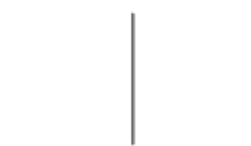

Repetição

\begin{abstract}
A mensagem de instância secundária repete
a mensagem de instância primária. Por serem meios diferentes (texto/imagem) a percepção do leitor é de que a mesma mensagem

está sendo repetida de outro modo.
\end{abstract}

Figura 1. Interação geradora de redundância - inferências a partir de Linden (2011). Fonte: Costa, 2021, no prelo.

Já as relações de colaboração são provocadas por interações de seleção, revelação, completude e amplificação (Figura 2).

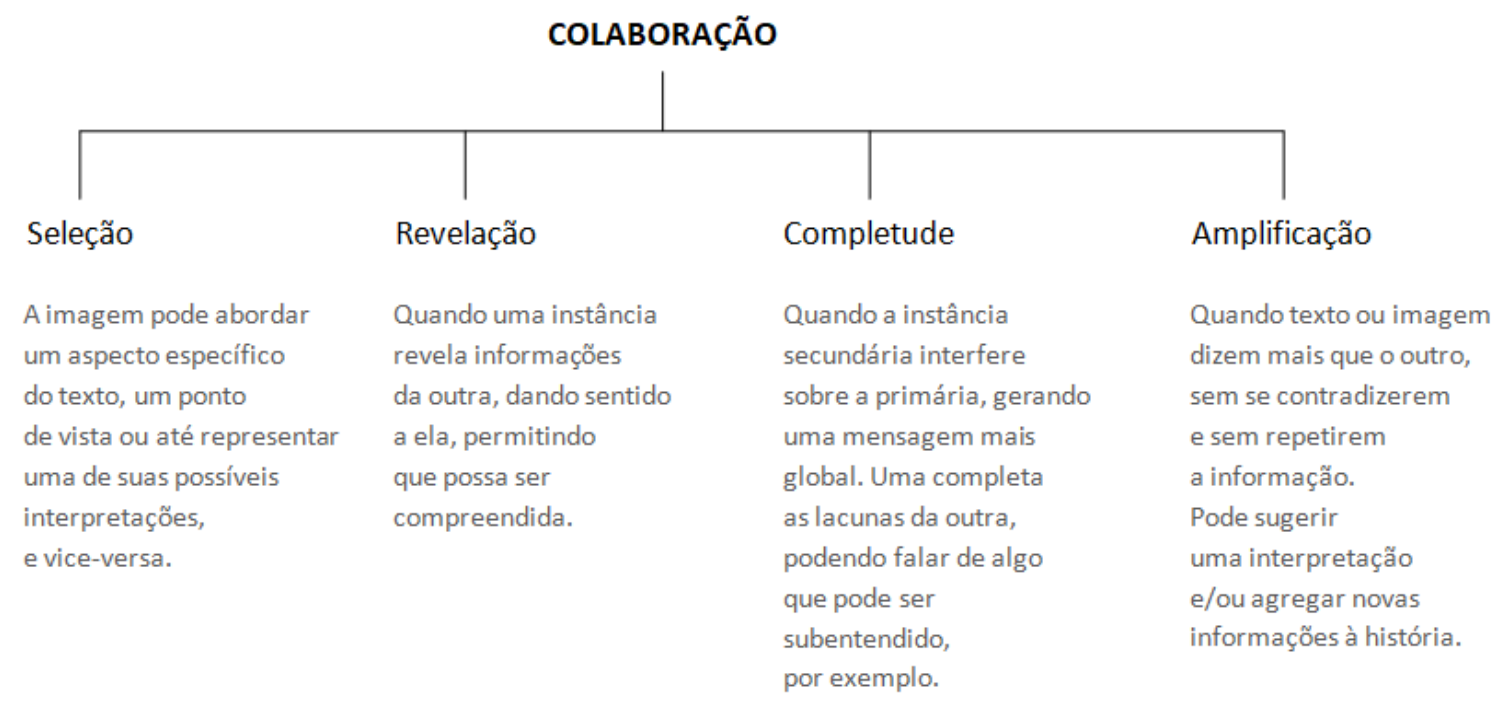

Figura 2. Interações geradoras de colaboração - inferências a partir de Linden (2011). Fonte: Costa, 2021, no prelo.

Por fim, as relações de disjunção podem ser provocadas pela interação de contraponto e por interação inexistente (Figura 3). 


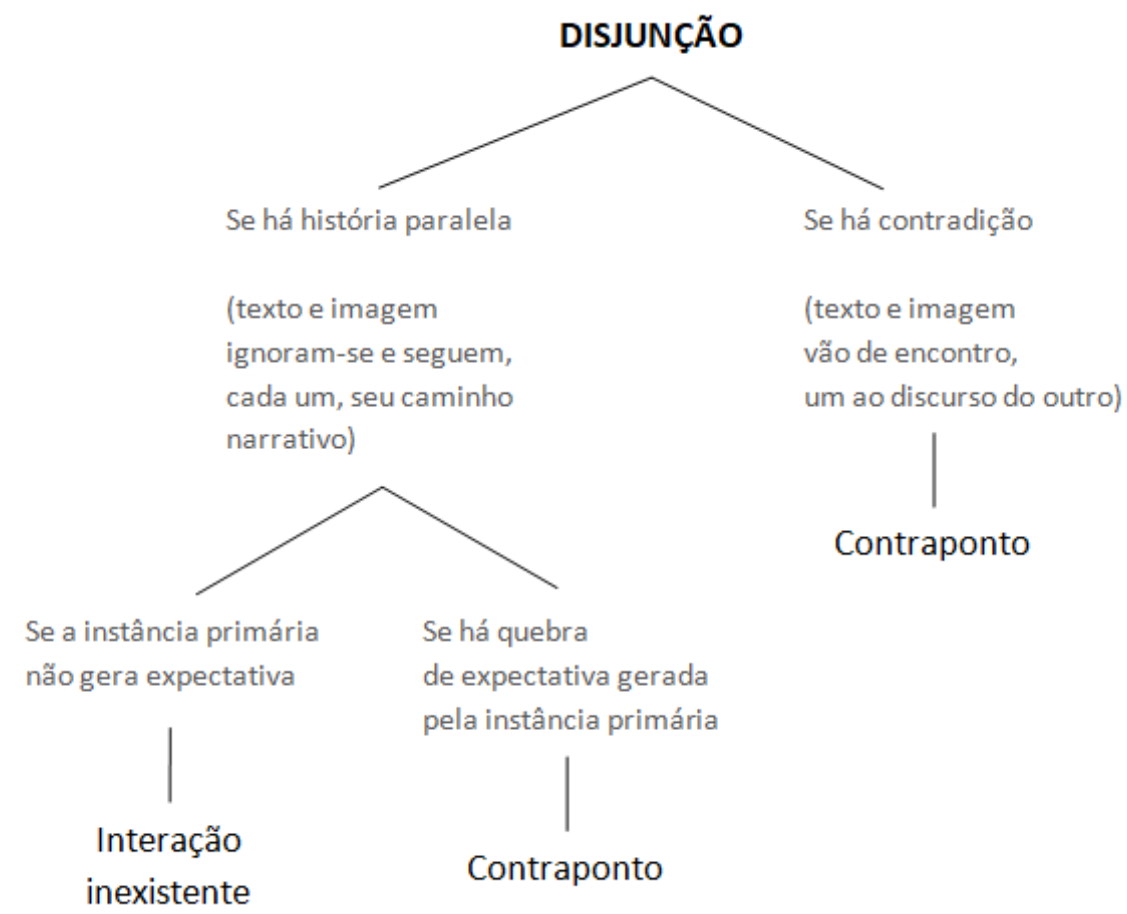

Figura 3. Interações geradoras de disjunção - inferências a partir de Linden (2011). Fonte: Costa, 2021, no prelo.

\section{Estratégia inferencial de leitura}

Um modo de leitura definido, como a estratégia inferencial de Tavares (2019), própria para o livro ilustrado, é um bom aporte contribuinte para a clarificação de uma análise qualitativa como a de Linden (2011) num contexto científico.

A consideração de Tavares (2019) sobre a leitura contempla o caráter subjetivo do leitor, que realiza inferências através de seus conhecimentos prévios e daqueles adquiridos no ato da leitura em prol da compreensão do livro, além de "[...] tentar predizer do que trata o texto construindo sentidos para ele" (Ibid., p. 184). A estratégia propõe a inferência constante sobre o sentido da história pelo questionamento do significado dos elementos pictóricos e textuais apresentados nas páginas do livro. Segundo a autora, "[...] ao centrar nossa leitura nas possibilidades que o exercício de inferência nos traz, devemos considerar os elementos gráficos relacionando-os aos dados do texto e às informações que podem ser percebidas como itens na construção dos sentidos" (Ibid., p. 194).

Costa (2021, no prelo) considera que o uso desta estratégia contribui fortemente com a identificação das relações de primazia no livro infantil ilustrado que, por sua vez, contribuem com a identificação das interações, consequentemente permitindo a identificação das relações texto-imagem conforme Linden (2011). 
Costa (2021, no prelo) também pondera que a subjetividade inevitavelmente presente na leitura tem sua interferência na interpretação de cada indivíduo, o que significa que pesquisadores diferentes podem registrar resultados diferentes, mesmo utilizando a mesma categorização e método de leitura propostos. Na área do Design da Informação, esta presença da subjetividade do indivíduo é evidenciada por Souza et al. (2016). Para manter a clareza científica, é importante que o pesquisador registre sua interpretação de cada relação texto-imagem do livro, de preferência expondo seus questionamentos inferenciais.

\section{Aplicação do modelo analítico}

Para exemplificar a aplicação do modelo analítico, usaremos o livro $A$ menina do picolé azul2 . Devido ao espaço limitado deste artigo, exemplificaremos com as duas primeiras relações texto-imagem da história, conforme registrados por Costa (2021, no prelo) em sua pesquisa.

Começaremos com as páginas 6-7 (Figura 4):

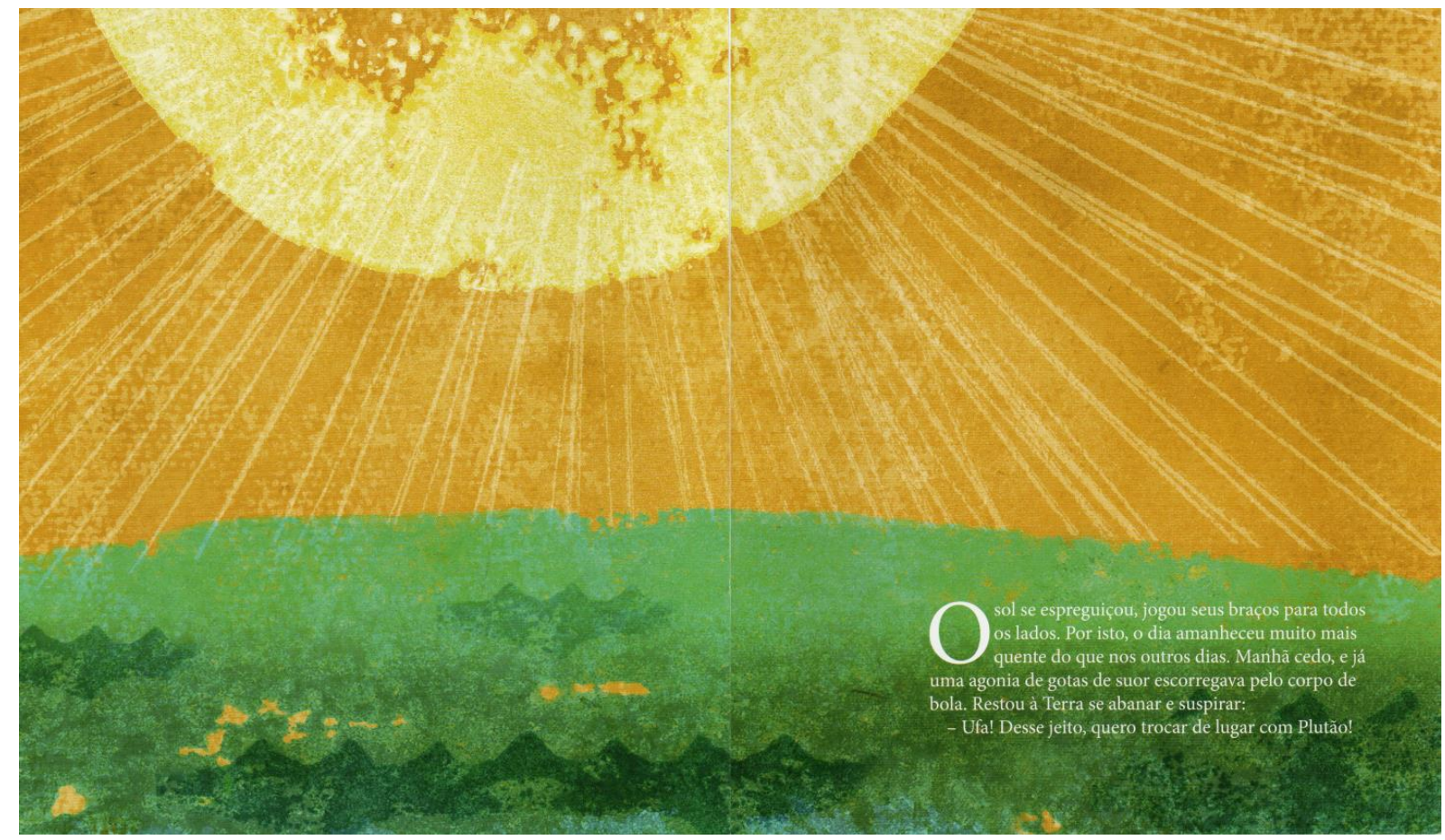

Figura 4. Primeira dupla de $\boldsymbol{A}$ menina do picolé azul. Fonte: Pieiro, 2016, p. 6-7.

Análise: Aqui a imagem é inegavelmente a instância primária. Vemos o sol amarelo-claro, com raios extremamente alongados para todos os lados - por que são representados assim? A superfície verde seria um mar? O texto, como instância secundária, inicia a história contando que "O sol se espreguiçou, jogou seus braços para todos os lados". Isso clarifica os raios solares alongados, saindo da estrela e chegando até a superfície verde. As palavras indicam que o dia estava mais quente 
que o normal, que mesmo de manhã cedo, a Terra já suava num calor tamanho que preferiria trocar de lugar com Plutão. O céu amarelado evidenciaria esse calor extremo, ou seria indicativo da iluminação do nascer do sol? A altura do astro no céu, que apesar da proximidade com a água, não consegue ser mostrado por toda a página, deixa-nos ponderando. Neste caso, assumimos a primeira opção. É curioso que o texto não dependa da imagem, sendo a imagem que depende do texto. Dada a posição de primazia estabelecida, julgamos que o texto - como instância secundária - revela informações cruciais para entendermos a imagem e fazermos sentido desta dupla. A relação que se estabelece é de colaboração.

Diagramação: Associação.

Função do texto: Ligação.

Relação entre texto e imagem: Colaboração.

Modo de interação entre texto e imagem nessa relação: Revelação do texto em relação à imagem.

Nas páginas 8-9 (Figura 5), continua-se:

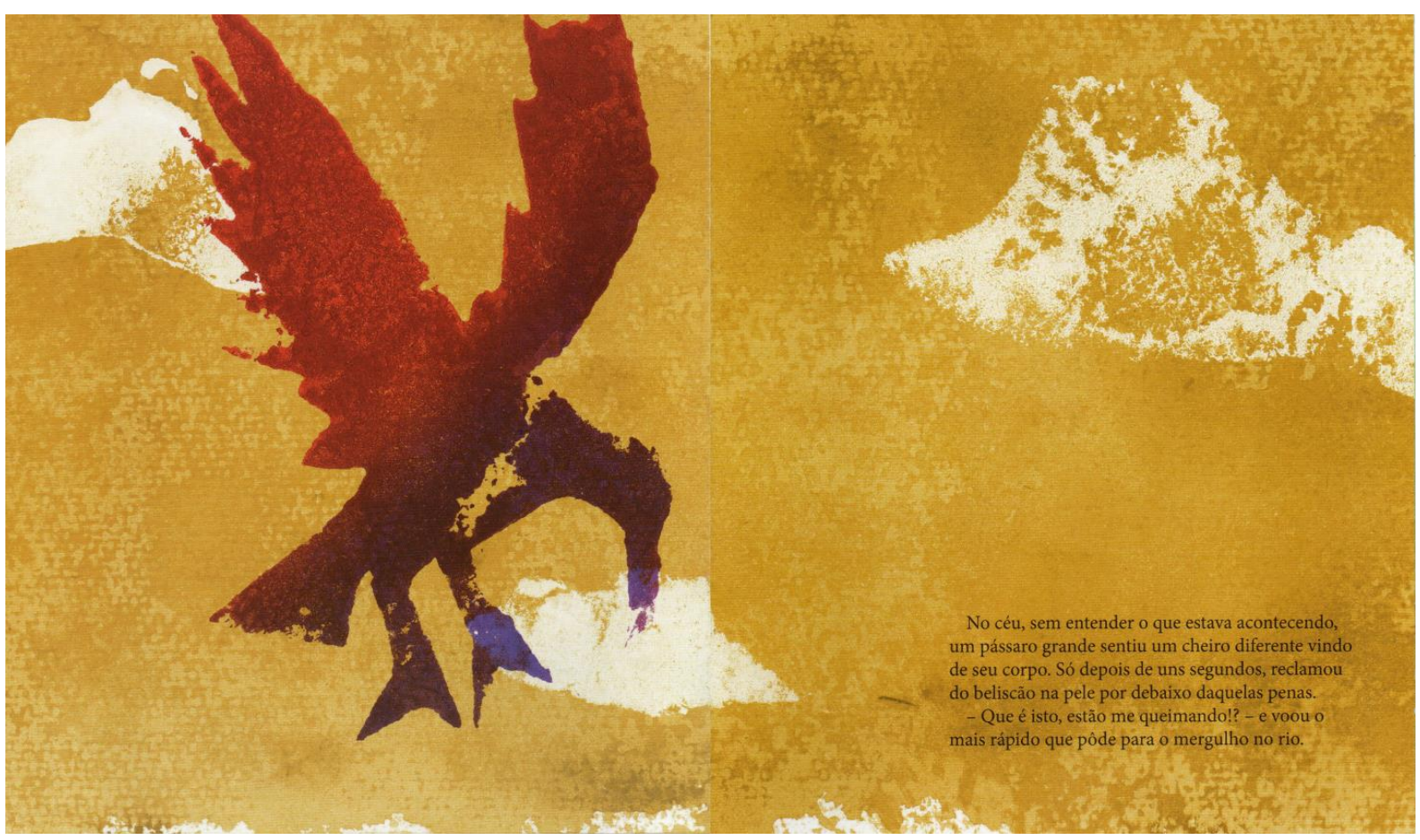

Figura 5. Segunda dupla de $A$ menina do picolé azul. Fonte: Pieiro, 2016, p. 8-9.

Análise: Como na dupla anterior, a imagem, em maior destaque, assume instância primária, enquanto o texto, no canto inferior direito da página ímpar, assume instância secundária. Na ilustração, um pássaro avermelhado voa num céu ainda amarelo com algumas nuvens. 
Se a hipótese da representação do céu amarelo indicar calor extremo se sustentar, então a sensação ainda pode estar presente nesta dupla. Há alguma razão para o pássaro ser avermelhado? As palavras contam que ele sentiu um "beliscão na pele" por conta do calor, e que procede a questionar a situação e mergulhar no rio. Isso ajuda a sustentar o simbolismo do céu amarelado, sugere que a cor vermelha do pássaro possa indicar que ele estava sendo queimado e atualiza a informação sobre a água na dupla anterior, que poderia estar representando um rio ao invés do mar. Vindo depois da imagem, o texto liga esta dupla com a anterior e traz informações que não estavam presentes nela: a incompreensão do pássaro sobre a situação, a percepção de "um cheiro diferente vindo de seu corpo", a sensação de beliscão na pele e a intenção de mergulhar no rio. O simbolismo da imagem permitiria considerá-la como em interação de amplificação em relação ao texto, mas por este ser instância secundária e atuar sobre a compreensão da instância primária, julgamos que a interação desta dupla é de revelação do texto em relação à imagem, dada a relação de primazia e o fato da imagem, neste caso, necessitar do aporte das palavras.

Diagramação: Associação.

Função do texto: Ligação.

Relação entre texto e imagem: Colaboração.

Modo de interação entre texto e imagem nessa relação: Revelação do texto em relação à imagem.

Adiante no livro, depois de uma cena no mar nas páginas 10-11, as páginas 12-13 apresentam novamente o céu amarelado. A partir das páginas 22-23, o fundo começa a ficar azul pela menina ter pedido um picolé e, nas páginas $24-25$, vemos pássaros roxo-escuros voando sob um céu azul. Tudo isso sustenta a inferência sobre o simbolismo inicial, de um céu amarelado sugerindo calor extremo.

Estas breves demonstrações evidenciam o que (COSTA, 2021, no prelo) considera uma dinâmica comunicacional presente no livro ilustrado, onde uma instância da comunicação pode omitir uma informação cuja representação é assumida pela outra; jogo de omissões já constatado por Sipe (2010) e Linden (2011).

\section{Considerações finais}

A estratégia inferencial de leitura de Tavares (2019) é ferramental importante na identificação da primazia das instâncias da comunicação no livro. Junto à categorização de Linden (2011), ambas ressaltam a dinâmica comunicacional do livro ilustrado sob o olhar analítico do designer da informação. É assim que começamos a entender como ocorre a dinâmica entre o discurso imagético 
e textual que podem convergir em interdependência para formar um sentido único nas páginas do livro ilustrado.

Ressaltamos, conforme Costa (2021, no prelo), que apesar da categorização de Linden (2011) abordada se aplicar aos elementos textuais, Tavares (2019) sugere que a leitura do livro se inicie pela capa, e assim deve fazer o pesquisador, porque mesmo os elementos externos do livro podem ajudar a criar um contexto que provoque inferências no ato da leitura dos elementos textuais.

Esperamos que o ferramental analítico apresentado possa munir os profissionais interessados no estudo do livro ilustrado e que, lançando um olhar sobre a configuração da mensagem, constitua contribuição metodológica para o campo do Design da Informação frente a esse objeto de pesquisa.

\section{Agradecimento}

O presente trabalho foi realizado com apoio da Coordenação de Aperfeiçoamento de Pessoal de Nível Superior - Brasil (CAPES) - Código de Financiamento 001.

\section{Referências}

COSTA, Guilherme Mendes Cahú. Geração de interdependência entre texto e imagem através de suas relações no livro infantil ilustrado. Dissertação (Mestrado em Design em andamento) Universidade Federal de Pernambuco. Orientadora: Solange Galvão Coutinho. Recife, 2021.

JACOBSON, Robert. Introduction: Why information design matters. In: JACOBSON, Robert (Ed.). Information Design. Cambridge: MIT Press, 1999, p. 1-10.

LINDEN, Sophie Van der. Para ler o livro ilustrado. Trad. Dorothée de Bruchard. São Paulo: Cosac Naify, 2011.

PIEIRO, Jorge. A menina do picolé azul. Ilustrações: Adriel Contieri. Recife: Cepe, 2016.

REDIG, Joaquim. Não há cidadania sem informação, nem informação sem design. InfoDesign Revista Brasileira de Design da Informação, v. 1, n. 1, p. 58-66, 2004.

SIPE, Lawrence R. Learning from illustrations in picturebooks. Leitura em Revista, Rio de Janeiro, n. 1, p. 71-84, ago, 2010. Disponível em: https://iiler.puc-rio.br/ler_anteriores/LER-1.pdf. Acesso em: 22 jul. 2021.

SOCIEDADE BRASILEIRA DE DESIGN DA INFORMAÇÃO (SBDI). Brasil, 2020. Disponível em: http://www.sbdi.org.br/definicoes. Acesso em: 12 ago. 2021.

SOUZA, Eduardo A.; OLIVEIRA, Gabriela Araujo; MIRANDA, Eva Rolim; COUTINHO, Solange Galvão; FILHO, Gentil Porto; WAECHTER, Hans da Nóbrega. Alternativas epistemológicas para o design da informação: a forma enquanto conteúdo. InfoDesign - Revista Brasileira de Design da Informação, v. 13, n. 2, p. 107-118, 2016.

TAVARES, Márcia. Estratégia inferencial para ler o livro ilustrado. Revista Graphos, v. 21, n. 1, p. 176196, 2019. 


\footnotetext{
${ }^{1}$ A pesquisa Geração de interdependência entre texto e imagem através de suas relações no livro infantil ilustrado será defendida em outubro de 2021.

${ }^{2}$ A Menina do Picolé Azul. Texto: Jorge Pieiro; ilustrações: Adriel Contieri; edição: 2016, Cepe Editora.
} 